\title{
Present-bias in different income groups
}

\author{
Citation for published version (APA):
}

Can, B., \& Erdem, O. (2013). Present-bias in different income groups. Maastricht University, Graduate School of Business and Economics. GSBE Research Memoranda No. 008 https://doi.org/10.26481/umagsb.2013008

Document status and date:

Published: 01/01/2013

DOI:

10.26481/umagsb.2013008

Document Version:

Publisher's PDF, also known as Version of record

\section{Please check the document version of this publication:}

- A submitted manuscript is the version of the article upon submission and before peer-review. There can be important differences between the submitted version and the official published version of record.

People interested in the research are advised to contact the author for the final version of the publication, or visit the DOI to the publisher's website.

- The final author version and the galley proof are versions of the publication after peer review.

- The final published version features the final layout of the paper including the volume, issue and page numbers.

Link to publication

\footnotetext{
General rights rights.

- You may freely distribute the URL identifying the publication in the public portal. please follow below link for the End User Agreement:

www.umlib.nl/taverne-license

Take down policy

If you believe that this document breaches copyright please contact us at:

repository@maastrichtuniversity.nl

providing details and we will investigate your claim.
}

Copyright and moral rights for the publications made accessible in the public portal are retained by the authors and/or other copyright owners and it is a condition of accessing publications that users recognise and abide by the legal requirements associated with these

- Users may download and print one copy of any publication from the public portal for the purpose of private study or research.

- You may not further distribute the material or use it for any profit-making activity or commercial gain

If the publication is distributed under the terms of Article $25 \mathrm{fa}$ of the Dutch Copyright Act, indicated by the "Taverne" license above, 


\section{Maastricht University}

Burak Can, Orhan Erdem

Present-Bias in Different I ncome Groups

RM/ 13/008

\section{GSBE}

Maastricht University School of Business and Economics

Graduate School of Business and Economics

P.O Box 616

NL-6200 MD Maastricht

The Netherlands 


\title{
Present-Bias in Different Income Groups
}

\author{
Burak Can* Orhan Erdem ${ }^{\dagger \ddagger}$ \\ Preliminary Draft: February 2013
}

\begin{abstract}
The excessive use of credit cards and increasing consumer borrowing has been a major problem. Laibson (1997) suggests the present-bias problem as one of the driving forces of excessive borrowing. Shefrin and Thaler (1988) suggest that self-control underlies national borrowing/savings rate. We conduct a survey to check for present-bias as well as self-control problems among individuals in Turkey. Our findings show that different income groups have similar discount factors, i.e., impatience levels, but very different degrees of dynamic inconsistencies, i.e. present-bias levels. In particular, $29.4 \%$ of low-income individuals exhibit present-bias whereas this is down to $6.4 \%$ for high-income individuals. Using the parameters we achieve through the surveys, policymakers can design appropriate commitment devices for time-inconsistent individuals to ensure a sustainable level of aggregate saving and financial investment.
\end{abstract}

JEL Classification: C93, D14, D91

Keywords: Self-control, present-bias, time preferences, quasi-hyperbolic discounting

\footnotetext{
${ }^{*}$ Maastricht University, School of Business and Economics, e-mail: b.can@maastrichtuniversity.nl

${ }^{\dagger}$ Borsa İstanbul, Research Department, e-mail: orhan.erdem@imkb.gov.tr

${ }^{\ddagger}$ The views and opinions in this article belong to the author(s) and do not necessarily reflect those of the Borsa İstanbul management and/or its departments.
} 


\section{Introduction}

According to world bank database, the worldwide average savings rate has been decreasing, and has reached to a 35-year historical minimum, $19 \%$ in 2009. The decreasing savings ratio is of special importance especially in developed countries, and has been discussed in various studies. Hershfield (2011) attribute this decreasing rates to the increasing life expectancy. That is, people people live longer, and hence experience longer retirement period compared to past, but their saving behavior cannot keep pace by saving more for longer retirement period. Discounting is the key aspect in savings behavior since savings can be perceived as choices over time. Considerable amount of research in finance, economics and psychology show that people's preferences, and hence discounting factor, change over time. This phenomenon, which is referred as time inconsistency, and its consequences have been examined both by experiments and field studies. Some of these researches have shown that short-run discount rates are by far higher than long-run rates (see Thaler (1981) for instance). Harrison et al. (2002) show that discount rates differ among households for a given time horizon as well as across time horizons for given households. Using field data instead of experiments, Laibson et al. (2007) also reject the hypothesis that the short-run discount rate is equal to the long-run discount rate.

We analyze the behavioral aspects of failure to save, in particular the dynamic inconsistency in time preferences. We are interested in the reversal of time preferences as a dynamic inconsistency. Kirby and Herrnstein (1995) show that individuals exhibit a reversal of preferences when choosing between a smaller-sooner and a larger-later reward. The "smaller" reward is preferred (presentbias) if it offers an immediate payoff, whereas the "larger" reward is preferred if both options are delayed. Similar findings are of particular interest to the finance literature, since self-control underlies the national saving rate (Shefrin and Thaler, 1988). Hence, a deeper understanding of self-control problems would contribute to increased national savings. Besides, a number of studies suggest that time inconsistency also drives credit card borrowing (Laibson, 1997; Fehr, 2002; Heidhues and Köszegi, 2008). These results have inspired researchers to improve standard exponential discounting which assumes a constant discount rate in time. One of the commonly used formulations of such time preferences is based upon a quasi-hyperbolic structure (for example Laibson (1997); O’Donoghue and Rabin (1999)). Using such a model, Meier and Sprenger (2010) find that people with dynamically inconsistent preferences have higher active borrowing levels. They also argue that the present-biased individuals have significantly higher credit card debt.

Frederick et al. (2002) suggest that the key to understand the intertemporal choice is finding the right discount rate. Therefore using a questionnaire, similar to that of Meier and Sprenger (2010) with imaginary monetary outcomes, we aim to calculate the discount factor (level of impatience) and to measure the present-bias in different income groups. By doing so, we wish to highlight the income effect on individuals' discounting differences. A quasi-hyperbolic discounting model (see Laibson (1997)) is used to pursue this aim. This model allows for inconsistent individuals who think they will save in the future but fail to accomplish that when the future arrives. A representative random sample of 65 subjects from Turkey is used for the survey which is distributed to two income groups; low and high. The former group is randomly selected among workers from a factory in İstanbul, whereas the members of the latter are randomly selected from a financial institute also in İstanbul. We show that discount factors in fact do not differ with respect to income groups. However there is a significant evidence that the level of present bias is different across income groups. The findings show that the ratio of people with dynamic inconsistency (present-bias) is much higher in the low 
income group (29.4\%) than in the high income group (6.4\%).

Using the parameters we achieve through the surveys, we can recommend a commitment device to policy-makers to ensure a sustainable level of aggregate saving and financial investment for timeinconsistent individuals. This especially becomes important under the finding that low income individuals require more "nudge" than those with high income.

The paper proceeds as follows: in Section 2, we discuss the quasi-hyperbolic model and its Samuelsonian predecessor. We discuss the survey, the dataset, and the variables together with an example in the end. Section 3 provides the numerical results regarding the impatience levels and the present-bias in different income groups. Section 4 concludes the paper with a brief discussion of the findings.

\section{The Model}

It is natural that one chooses an earlier monetary reward to a later one of equal size. Depending on the level of impatience of an individual, there might be a certain decrease in the earlier reward which makes the individual indifferent between the earlier and later rewards. Subjective impatience of an individual over a time horizon can be found out by his/her indifference between two such rewards. In the standard Samuelson (1937) utility discounting, the rewards on a timeline is discounted exponentially. An overall time preference model hence looks as follows:

$$
U=u_{0}+\delta u_{1}+\delta^{2} u_{2}+\delta^{3} u_{3}+\ldots
$$

This model assumes that, given the subjective discount rate of an individual $\delta$, the subjective utility of a reward $u_{t}$ in time $t$, in the future, is discounted by $\delta^{t}$ to present time. For the sake of simplicity, we use monetary rewards as the utility itself, e.g., the utility gained by a payment of 5 TL 1 equals 5. Therefore, a reward of size $x$ next year is only as good as a reward now equal to $\delta x$. The disadvantage of this model is that it assumes a constant discounting level for individuals. It has been shown, as discussed in the introduction, that many individuals change the way they discount when the decisions involve a choice between now and next year instead of two points in time in the future, e.g., a choice between 6 years and 7 years from now.

Laibson (1997) suggested a revision of the standard model by incorporating a present-bias element. In this model, decisions involving rewards now and in the future are differently discounted that decisions involving two future payments. This extension of the standard model to quasihyperbolic model is given below:

$$
U=u_{0}+\beta\left(u_{1}+\delta u_{2}+\delta u_{3}+\ldots\right)
$$

The novelty of this formulation of time preferences is that it provides room for explaining the behavior of so-called "time-inconsistent" individuals. Assume that the individuals are asked to choose between two payments; one in the 6th year, and one in the 7th year. Then the decision will involve comparison of the following: $\beta \delta^{6} u_{6}$ and $\beta \delta^{7} u_{7}$. When simplified, this is effectively a choice between $u_{6}$ and $\delta u_{7}$. In that case it is identical to standard discounting model being used since Samuelson. However a decision between now and next year is different: $u_{0}$ and $\beta \delta u_{1}$. In case an

\footnotetext{
${ }^{1}$ TL: Turkish Lira, the native currency of the subjects who responded to the survey. At the time the survey was conducted the real exchange rate of the Turkish Central Bank was: 1 US $\$=1.8099 \mathrm{TL}$
} 
individual has present-bias, the decision involving present time is favored. This favoring is done by discounting the later payment by an additional parameter $\beta$ on top of $\delta$.

\subsection{The subjects and the survey}

We use a questionnaire which was implemented also in Meier and Sprenger (2010). The survey is conducted in Turkish, subjects' native language, and is answered by 65 . We categorized the subjects into two groups according to their income levels; low-income (LI) and high-income (HI). Individuals are considered as low-income if their monthly income is below 2000 TL. More than $70 \%$ of the individuals in the LI group do not own a car or have rental costs. Individuals with incomes above 2000 TL constitute the HI groun ${ }^{2}$. The LI subjects comprised of 31 individuals whereas the HI subjects amount to 34 . The ages of the subjects vary between 21 and 56, with a (rounded) average of 31.36 and a median age of 29 .

The survey consisted of three parts (see Table 2 in Appendix A.1). The first part of the survey asks, in 6 questions, the subjects to choose between two options. The point which subjects switch from Option 1 to Option 2, in this part, gives us the interval of discounting between today and next month. The second part of the survey asks, in 7 questions, the subjects to choose between two options. The point which subjects switch from Option 1 to Option 2, in this part, gives us the interval of discounting between today and 6 months later. The last part of the survey asks, in 6 questions, the subjects to choose between two options. The point which subjects switch from Option 1 to Option 2, in this part, gives us the interval of discounting between 6 months later and 7 months later.

To preserve the consistency within the data, we filtered some of the individuals from the initial subject pool which was slightly larger than 65. In particular individuals who always answered every question with 1 (such as a person who would always ask for the earlier payment whatever the difference is between earlier and later payment), and those who always answered every question by 2 (those who would always go for the later payment, regardless of time difference and the payment difference).

\subsection{Dataset and the variables}

In the quasi-hyperbolic discounting model, we have one discount factor and one present bias parameter from the questions in Part 1 and $2\left(\delta_{1}\right.$ and $\left.\beta_{1}\right)$. We also have one discount factor and one present bias parameter from the questions in Part 1 and $3\left(\delta_{2}\right.$ and $\left.\beta_{2}\right)$. The average of the two discount factors gives us $\delta$ and the average of the two present bias parameters gives us $\beta$ which we shall use as independent variables in the quasi-hyperbolic discounting model. The detailed derivation of these parameters can be found in Example 1.

- $\delta_{1}$ and $\beta_{1}$ : The discount factor and the present bias parameter induced by the indifference acquired from the first 6 questions in Part 1 and the 7 questions in Part 2 (the first 6 questions are discounted by $\beta_{1} \delta_{1}$ and the next 7 questions are discounted by $\left.\beta_{1} \delta_{1}^{6}\right)$.

\footnotetext{
${ }^{2}$ Note that the labeling does not necessarily reflect the wealth of individuals. Since the number of subjects who are interviewed are limited, we did not categorize them into more income groups.
} 
- $\delta_{2}$ and $\beta_{2}$ : The discount factor and the present bias parameter induced by the indifference acquired from the first 6 questions in Part 1 and the last 6 questions in Part 3 (the first 6 questions are discounted by $\beta_{2} \delta_{2}$ and the last 6 questions are discounted by $\delta_{2}$ ).

- $\delta$ : This is the average of the two discount factors $\left(\delta_{1}\right.$ and $\left.\delta_{2}\right)$ described above.

- $\beta$ : This is the average of the two present bias parameters $\left(\beta_{1}\right.$ and $\left.\beta_{2}\right)$ described above.

We first look for individuals with a dynamic time-inconsistency, i.e., self-control problem or present-bias. Such individuals exhibit different switching points in the first and the third part of the survey. In particular, an individual with present-bias, exhibits a more delayed switch from (i) to (ii) in Part 1 than in Part 3. Although in both parts the time-delay between options is one month, the questions in Part 1 involves an option "today", i.e., present time. This causes the individuals with self-control problems delay their switch for the higher and later reward.

We define the critical points for each part, where individuals switch from option (i) to option (ii). For instance, in Part 1, assume an individual prefers 65 TL today to 80 TL one month later. If this individuals prefers (in the next question) $80 \mathrm{TL}$ one month later to 60 TL today, then we say the critical points are $60 \mathrm{TL}$ and $65 \mathrm{TL}$. We take the average of those critical points and assume it to be the level of payment that would steer indifference between options (i) and (ii), e.g., indifference between 62.5 today and 80 one month later.

Given the critical points in each part, the levels of indifference between the two options in (i) and (ii) lead to following formulations. In Part 1, the two options $u_{0}$ and $u_{1}$ lead to: $u_{0}=\beta \delta \times u_{1}$. In Part 2, the two options $u_{0}$ and $u_{6}$ lead to: $u_{0}=\beta \delta^{6} \times u_{6}$. In Part 3 , the two options $u_{6}$ and $u_{7}$ lead to: $u_{6}=\delta \times u_{7}$. Now we provide an example to show the derivation of the parameters.

Example 1. Consider the answers of an individual below. See appendix for the questionnaire.

Part 1: Individual $X$, switched from option (i) to (ii) when the reward in option (i) fell from 65 to 60 today, versus a reward of 80 next month in option (ii).

Part 2: Individual $X$, switched from option (i) to (ii) when the reward in option (i) fell from 60 to 50 today, versus a reward of 80 in 6 months in option (ii).

Part 3: Individual $X$, immediately switched from option (i) to (ii) when the reward in option (i) was 75 in 6 months, versus a reward of 80 in 7 months.

To find the critical points, we assume the average in Part 1, i.e., 62.5 today, to be the indifference level with 80 tomorrow. Similarly in Part 2, we assume 55 today to be the indifference level with 80 in 6 months. In Part 3, we assume 75 in 6 months to be the indifference level to 80 in 7 months. Then we check whether the agent shows present bias, i.e., if the individual switches from option (i) to option (ii) earlier in Part 3 than in Part 1.

This individual makes the switch to higher payment in Part 3 immediately, whereas same time horizon becomes much more tempting in Part 1 since it involves present-time (the switch to higher payment in Part 1 occurs only when the payment now gets as low as 60 TL). The calculations proceed as follows with decimals rounded up to 3 digits: 
The system of equations from the answers to Part 1 and Part 2 leads to:

(Discount parameter 1: $\delta_{1}$ ) Part 2 and Part 1: $u_{0}=\beta \times \delta_{1}^{6} u_{6}$ and $u_{0}=\beta \times \delta_{1} \times u_{1}$. Then, $\beta \times \delta_{1}^{6}=u_{0} / u_{6}=55 / 80$ and $\beta \times \delta_{1}=u_{0} / u_{1}=62.5 / 80$. Combining these two leads to $\delta_{1}^{5}=55 / 62.5$. Therefore $\delta_{1}=0.974$.

(Present-bias parameter 1: $\beta_{1}$ ) Part 1: $u_{0}=\beta_{1} \times \delta \times u_{1}$. Using $\delta_{1}$ and solving for the data leads to $\beta_{1}=u_{0} /\left(\delta_{1} \times u_{1}\right)$. Therefore $\beta_{1}=62.5 /\left(\delta_{1} \times 80\right)=0.801$.

The system of equations from the answers to Part 1 and Part 3 leads to:

(Discount parameter 2: $\delta_{2}$ ) Part 3: $u_{6}=\delta_{2} \times u_{7}$, which implies that $75=\delta_{2} \times 80$. Therefore $\delta_{2}=0.937$.

(Present-bias parameter 2: $\beta_{2}$ ) Part 1 and Part 3: $u_{0}=\beta \times \delta \times u_{1}$ and $u_{6}=\delta \times u_{7}$. Using $\delta_{2}$ and solving for the data leads to $\beta_{2}=\left(u_{0} / u_{1}\right) /\left(u_{6} / u_{7}\right)=(62.5 / 80) /(75 / 80)$. Therefore $\beta_{2}=.0 .833$

The systems of equations derived from the 3 parts in the questionnaire gives us 2 parameters for both the discount parameter $\delta$ and for the present-bias parameter. Note that for the individuals who do not show present-bias, the latter parameter trivially becomes 1 and hence the model simplifies into Samuelson type of time-preference.

To sum up, the average discount parameter of individual $X$ is $\delta=\left(\delta_{1}+\delta_{2}\right) / 2=0.956$. The average present-bias individual $X$ exhibits is $\beta=\left(\beta_{1}+\beta_{2}\right) / 2=0.817$.

\section{Results}

We provide the results for both groups, high income (HI) and low income (LI), together with the total population (Total). The values are given in 3-digit decimals. We first provide discount factors when present-bias is completely ignored, i.e., using the conventional standard exponential discounting. Thereafter we show our findings with the quasi-hyperbolic discounting model.

\subsection{Impatience under standard exponential model (without present-bias pa- rameter)}

As explained in the introduction, the standard model in Samuelson (1937) neglects the self-control problem which is known as present-bias. Since there is only a single parameter in this exponential model, i.e., $\delta$, each part in the questionnaire leads to a (possibly different) discount factor; $\delta_{1}, \delta_{2}$, and $\delta_{3}$. We take the average of these discount factors to produce an approximation of the individual discount factors.

When the present bias parameter is not taken into account the standard exponential model of time preferences induces the following discount factors for the two groups:

- HI: 31 individuals exhibit on average a discount factor, $\delta=0.833$,

- LI: 34 individuals exhibit on average a discount factor, $\delta=0.810$,

- Total: 65 individuals exhibit on average a discount factor, $\delta=0.821$.

Note that these findings imply that high-income individuals exhibit more impatience than the low-income individuals. However it turns out there might be an explanation for this rather unexpected outcome. Next we apply the quasi-hyperbolic model and check for present-bias. It turns out almost one third of low-income individuals exhibit present-bias whereas for high-income individuals this is the case for a small minority (2 out of 31 ). 


\subsection{Impatience and present-bias under quasi-hyperbolic model (with present- bias parameter)}

We check for self-control problems in the data and found in total 12 (10 in LI group and 2 in HI group) individuals with present-bias. $29.4 \%$ of low income individuals and $6.4 \%$ of high income individuals exhibit present-bias. The rest of the population is dynamically consistent and hence with no present-bias, i.e., $\beta=1$. Below is a summary of the data under quasi-hyperbolic model. For details see Table 3 in Appendix A.2.

- HI: 31 individuals exhibit on average a discount factor, $\delta=0.892$ and a present-bias parameter, $\beta=0.989$,

- LI: 34 individuals exhibit on average a discount factor, $\delta=0.893$ and a present-bias parameter, $\beta=0.954$,

- Total: 65 individuals exhibit on average a discount factor, $\delta=0.893$ and a present-bias parameter, $\beta=0.973$.

When we categorize the individuals with respect to whether they exhibit present-bias or not, we have the following values. The individuals with present-bias, $15.3 \%$ of the total population constitute an average discount factor of $\delta=0.911$ and an average present-bias of $\beta=0.854$. The rest of the population constitute an average discount factor of $\delta=0.888$ and naturally a present-bias of $\beta=1$.

\subsection{Minimal return rate to induce savings}

Consider an individual who discounts with $\delta$ for a one-month delay in a payment. In that case we say the minimal total return to trigger the savings decision for this individual is: $1 / \delta$. This corresponds to a net return rate of the following expression:

$$
r=\frac{1}{\delta}-1 \quad \text { (investing in the future) }
$$

Note that some individuals may exhibit present-bias. Due to this, the return rates which trigger these individuals to invest (or save) could be higher now than in the future. In the future the return rate they require to invest is equivalent to Equation 3 above. However, for decisions involving the present, the expression also is expanded by the present-bias parameter:

$$
r=\frac{1}{\beta \delta}-1 \quad \text { (investing now) }
$$

In Table A.2, we denote the return rate required today by $r_{\text {present }}$ and the rate for the future by, $r_{\text {future }}$. We provide these return rates both for present and future investment decisions. Obviously for individuals without present-bias, return rates for both decisions (present and future) are the same. Hence their values for Equations 3 and 4 are equal.

\subsection{The Personal Determinants of Present Bias and Impatience}

Here we seek the personal attributes of impatience $(\delta)$ and present bias $(\beta)$. Note that impatience decreases as $\delta$ increases. Similarly present bias (time-inconsistency or self-control) decreases as 
$\beta$ increases. The complete list of individual parameters for $\delta$ and $\beta$ can be found in Table 3 in Appendix A.2. We try to measure the effects of age and income within the total pool of subjects. The following two regression equation are estimated.

$$
\begin{aligned}
& \text { PresentBias }=\alpha_{1}+\alpha_{2} \times \text { age }+\alpha_{3} \times \text { income } \\
& \text { Impatience }=\alpha_{1}+\alpha_{2} \times \text { age }+\alpha_{3} \times \text { income }
\end{aligned}
$$

The estimated parameters of Equations 5 and 6 are summarized in Table 1 below.

\begin{tabular}{|c|c|c|}
\hline & $(\delta)$ Impatience & $(\beta)$ Present Bias \\
\hline Intercept & $0.845\left(^{*}\right)$ & $1.010\left(^{*}\right)$ \\
\hline Age & $0.001(* * *)$ & $-0.002\left(^{* *}\right)$ \\
\hline Income & 0.003 & $0.011\left(^{* * *}\right)$ \\
\hline \hline R-square & 0.04 & 0.15 \\
\hline
\end{tabular}

Table 1: The marks $\left({ }^{*}\right),\left({ }^{* *}\right),\left({ }^{* * *}\right)$ show the $1 \%, 5 \%, 10 \%$ significance levels respectively.

As it can be seen from the second column of Table 1, only Age is significant (at 10\% level) in the impatience regression. Therefore we can conclude that different income groups have similar impatience. However, both Age and Income are significant at 5\% and $10 \%$ respectively in the present-bias regression (third column of Table 1). As the results suggest, the present-bias parameter increases with income. This means present-bias (hence time-inconsistency) decreases as income increases. It is likely, then, that people with lower income are more easily tempted to spend in the present time. Note also that among the individuals with present-bias, $83 \%$ of them are from the low-income group. This makes the findings more striking as it is mainly the low-income individuals that require savings schemes and commitment devices to eliminate the effects of present-bias in their decision-making. The results in the third column reveals that the present bias parameter decreases with age. That is, older people have smaller present bias parameter, i.e. they tend to choose immediate monetary rewards as opposed to later rewards more than younger people do. This finding is also very consistent with the above argument. Younger people have more future-looking behavior than old people.

\section{Conclusion}

The decreasing savings ratio is of special importance especially in the developed countries. Here we attempt to point out a behavioral aspect of failure in savings: the present-bias of individuals. Although failure to save is not only a problem of the last decade, the concept is relatively new in finance literature.

This study shows that the failure in savings can also be explained by behavioral aspects of decision making. Our study clearly shows that in particular the low-income and old-age individuals suffer present-bias problem. These individuals, therefore, fail to make decisions today that might be more beneficial to them in the future, e.g., savings. This result can be explained by the fact that high-income or young individuals have stronger connection with their future selves. Joshi and Fast (2013) claims that power makes people more connected to their futures. In this sense, income 
and being young can be perceived as power. This is nevertheless good news since with proper commitment devices, such as offering present-biased individuals some saving schemes in the future, an increase in overall savings can be achieved. The commitment devices can be calibrated via the parameters such as the minimal return rate to induce savings, $r$.

In standard macroeconomic models, the first tool that comes to one's mind to induce savings can be performed via increasing the interest rates. However one can introduce commitment devices at the existing rates to boost the savings of people with present-bias (which are very likely to be from the poor side of the town). 


\section{A Appendix}

\section{A.1 The questionnaire}

1. Name:

Surname:

2. Date of Birth:

3. Do you own a car?

4. Do you pay rent for the house you live in?

5. Please state your monthly income:

[] $0-1000 \mathrm{TL}$ [] $1000-2000 \mathrm{TL}$ [] $2000-3000 \mathrm{TL}$

[ ] $3000-4000 \mathrm{TL}$ [] $4000-5000 \mathrm{TL}$ [] $5000-\ldots \mathrm{TL}$

6. Please answer the following 19 questions by ticking one option in each. You are requested to choose between payments in different points in time (today, in 1 month, in 6 months, or in 7 months).

\begin{tabular}{|c|c|c|}
\hline Part 1 & Option 1 (today) & Option 2 (1 month later) \\
\hline Question (1) & [] Payment today: $75 \mathrm{TL}$ & [] Payment 1 month later: $80 \mathrm{TL}$ \\
\hline Question (2) & [ ] Payment today: $70 \mathrm{TL}$ & [] Payment 1 month later: $80 \mathrm{TL}$ \\
\hline Question (3) & [ ] Payment today: $65 \mathrm{TL}$ & [] Payment 1 month later: $80 \mathrm{TL}$ \\
\hline Question (4) & [ ] Payment today: $60 \mathrm{TL}$ & [] Payment 1 month later: $80 \mathrm{TL}$ \\
\hline Question (5) & [ ] Payment today: 50 TL & [ ] Payment 1 month later: $80 \mathrm{TL}$ \\
\hline Question (6) & [ ] Payment today: $40 \mathrm{TL}$ & [ ] Payment 1 month later: $80 \mathrm{TL}$ \\
\hline Part 2 & Option 1 (today) & Option 2 (6 months later) \\
\hline Question (7) & [] Payment today: 75 TL & [] Payment 6 months later: $80 \mathrm{TL}$ \\
\hline Question (8) & [ ] Payment today: $70 \mathrm{TL}$ & [] Payment 6 months later: $80 \mathrm{TL}$ \\
\hline Question (9) & [ ] Payment today: $65 \mathrm{TL}$ & [ ] Payment 6 months later: $80 \mathrm{TL}$ \\
\hline Question (10) & [ ] Payment today: $60 \mathrm{TL}$ & [] Payment 6 months later: $80 \mathrm{TL}$ \\
\hline Question (11) & [ ] Payment today: $50 \mathrm{TL}$ & [ ] Payment 6 months later: $80 \mathrm{TL}$ \\
\hline Question (12) & [] Payment today: $40 \mathrm{TL}$ & [] Payment 6 months later: $80 \mathrm{TL}$ \\
\hline Question (13) & [ ] Payment today: $30 \mathrm{TL}$ & [] Payment 6 months later: $80 \mathrm{TL}$ \\
\hline Part 3 & Option 1 (6 months later) & Option 2 (7 months later) \\
\hline Question (14) & [] Payment 6 months later: $75 \mathrm{TL}$ & [] Payment 7 months later: $80 \mathrm{TL}$ \\
\hline Question (15) & [] Payment 6 months later: $70 \mathrm{TL}$ & [] Payment 7 months later: $80 \mathrm{TL}$ \\
\hline Question (16) & [] Payment 6 months later: $65 \mathrm{TL}$ & [] Payment 7 months later: $80 \mathrm{TL}$ \\
\hline Question (17) & [] Payment 6 months later: $60 \mathrm{TL}$ & [] Payment 7 months later: $80 \mathrm{TL}$ \\
\hline Question (18) & [ ] Payment 6 months later: $50 \mathrm{TL}$ & [ ] Payment 7 months later: $80 \mathrm{TL}$ \\
\hline Question (19) & [ ] Payment 6 months later: $40 \mathrm{TL}$ & [ ] Payment 7 months later: $80 \mathrm{TL}$ \\
\hline
\end{tabular}

Table 2: The questionnaire 


\section{A.2 Discount factors $\delta$ and present-bias parameters $\beta$}

\begin{tabular}{|c|c|c|c|c|c|c|c|c|c|}
\hline \multicolumn{5}{|c|}{ Low Income } & \multicolumn{5}{|c|}{ High Income } \\
\hline Ind. & $\beta$ & $\delta$ & $r_{\text {present }}$ & $r_{\text {future }}$ & Ind. & $\beta$ & $\delta$ & $r_{\text {present }}$ & $r_{\text {future }}$ \\
\hline 1 & 0.931 & 0.907 & 0.184 & 0.102 & 1 & 0.690 & 0.844 & 0.717 & 0.185 \\
\hline 2 & 0.817 & 0.956 & 0.280 & 0.046 & 2 & 0.962 & 0.942 & 0.103 & 0.062 \\
\hline 3 & 0.834 & 0.937 & 0.280 & 0.067 & 3 & 1 & 0.922 & 0.085 & 0.085 \\
\hline 4 & 0.817 & 0.956 & 0.280 & 0.046 & 4 & 1 & 0.902 & 0.109 & 0.109 \\
\hline 5 & 0.864 & 0.909 & 0.273 & 0.100 & 5 & 1 & 0.965 & 0.036 & 0.036 \\
\hline 6 & 0.931 & 0.907 & 0.184 & 0.102 & 6 & 1 & 0.902 & 0.109 & 0.109 \\
\hline 7 & 0.848 & 0.921 & 0.280 & 0.085 & 7 & 1 & 0.902 & 0.109 & 0.109 \\
\hline 8 & 0.798 & 0.871 & 0.439 & 0.148 & 8 & 1 & 0.965 & 0.036 & 0.036 \\
\hline 9 & 0.902 & 0.867 & 0.279 & 0.153 & 9 & 1 & 0.965 & 0.036 & 0.036 \\
\hline 10 & 0.854 & 0.922 & 0.271 & 0.085 & 10 & 1 & 0.958 & 0.043 & 0.043 \\
\hline 11 & 1 & 0.883 & 0.133 & 0.133 & 11 & 1 & 0.859 & 0.164 & 0.164 \\
\hline 12 & 1 & 0.914 & 0.094 & 0.094 & 12 & 1 & 0.946 & 0.057 & 0.057 \\
\hline 13 & 1 & 0.939 & 0.065 & 0.065 & 13 & 1 & 0.958 & 0.043 & 0.043 \\
\hline 14 & 1 & 0.859 & 0.164 & 0.164 & 14 & 1 & 0.902 & 0.109 & 0.109 \\
\hline 15 & 1 & 0.847 & 0.181 & 0.181 & 15 & 1 & 0.902 & 0.109 & 0.109 \\
\hline 16 & 1 & 0.922 & 0.085 & 0.085 & 16 & 1 & 0.902 & 0.109 & 0.109 \\
\hline 17 & 1 & 0.902 & 0.109 & 0.109 & 17 & 1 & 0.902 & 0.109 & 0.109 \\
\hline 18 & 1 & 0.926 & 0.080 & 0.080 & 18 & 1 & 0.902 & 0.109 & 0.109 \\
\hline 19 & 1 & 0.883 & 0.133 & 0.133 & 19 & 1 & 0.926 & 0.080 & 0.080 \\
\hline 20 & 1 & 0.939 & 0.065 & 0.065 & 20 & 1 & 0.939 & 0.065 & 0.065 \\
\hline 21 & 1 & 0.920 & 0.087 & 0.087 & 21 & 1 & 0.801 & 0.249 & 0.249 \\
\hline 22 & 1 & 0.898 & 0.113 & 0.113 & 22 & 1 & 0.787 & 0.271 & 0.271 \\
\hline 23 & 1 & 0.914 & 0.094 & 0.094 & 23 & 1 & 0.787 & 0.271 & 0.271 \\
\hline 24 & 1 & 0.878 & 0.139 & 0.139 & 24 & 1 & 0.787 & 0.271 & 0.271 \\
\hline 25 & 1 & 0.737 & 0.357 & 0.357 & 25 & 1 & 0.836 & 0.196 & 0.196 \\
\hline 26 & 1 & 0.737 & 0.357 & 0.357 & 26 & 1 & 0.878 & 0.139 & 0.139 \\
\hline 27 & 1 & 0.801 & 0.249 & 0.249 & 27 & 1 & 0.883 & 0.133 & 0.133 \\
\hline 28 & 1 & 0.822 & 0.216 & 0.216 & 28 & 1 & 0.902 & 0.109 & 0.109 \\
\hline 29 & 1 & 0.891 & 0.123 & 0.123 & 29 & 1 & 0.883 & 0.133 & 0.133 \\
\hline 30 & 1 & 0.951 & 0.052 & 0.052 & 30 & 1 & 0.883 & 0.133 & 0.133 \\
\hline 31 & 1 & 0.969 & 0.032 & 0.032 & 31 & 1 & 0.859 & 0.164 & 0.164 \\
\hline 32 & - & - & - & - & 32 & 1 & 0.908 & 0.102 & 0.102 \\
\hline 33 & - & - & - & - & 33 & 1 & 0.883 & 0.133 & 0.133 \\
\hline 34 & - & - & - & - & 34 & 1 & 0.883 & 0.133 & 0.133 \\
\hline Avg: & 0.955 & 0.893 & 0.183 & 0.125 & & 0.989 & 0.893 & 0.140 & 0.124 \\
\hline
\end{tabular}

Table 3: The complete data

The individuals with present-bias are put at the top of both low and high income groups. Note that values for $r_{\text {present }}$ and $r_{\text {future }}$ are different only for individuals with present-bias, i.e., individuals with $\beta<1$. For simplicity, all the decimals are restricted to 3 digits only. 


\section{References}

Fehr, E. (2002). The economics of impatience. Nature 415, 269-272.

Frederick, S., G. Loewenstein, and T. O'donoghue (2002). Time discounting and time preference: A critical review. Journal of economic literature 40(2), 351-401.

Harrison, G., M. Lau, and M. Williams (2002). Estimating individual discount rates in denmark: A field experiment. The American Economic Review 92(5), 1606-1617.

Heidhues, P. and B. Kőszegi (2008). Competition and price variation when consumers are loss averse. The American Economic Review, 1245-1268.

Hershfield, H. E. (2011). Future self-continuity: how conceptions of the future self transform intertemporal choice. Annals of the New York Academy of Sciences 1235(1), 30-43.

Joshi, P. D. and N. J. Fast (2013). Power and reduced temporal discounting. Psychological Science.

Kirby, K. and R. Herrnstein (1995). Preference reversals due to myopic discounting of delayed reward. Psychological Science 6(2), 83-89.

Laibson, D. (1997). Golden eggs and hyperbolic discounting. The Quarterly Journal of Economics 112(2), 443-478.

Laibson, D., A. Repetto, and J. Tobacman (2007). Estimating discount functions with consumption choices over the lifecycle. Technical report, National Bureau of Economic Research.

Meier, S. and C. Sprenger (2010). Present-biased preferences and credit card borrowing. American Economic Journal 2(1), 193-210.

O'Donoghue, T. and M. Rabin (1999). Doing it now or later. American Economic Review, 103-124.

Samuelson, P. (1937). A note on measurement of utility. The Review of Economic Studies 4(2), $155-161$.

Shefrin, H. and R. Thaler (1988). The behavioral life-cycle hypothesis. Economic inquiry 26(4), 609-643.

Thaler, R. (1981). Some empirical evidence on dynamic inconsistency. Economics Letters 8(3), 201-207. 